Supporting Information:

\title{
Gold nanorods as colorful chromogenic substrates for semiquantitative detection of nucleic acids, proteins and small molecules with the naked eye
}

Xiaoming $\mathrm{Ma}^{1}$, Zhitao Chen, ${ }^{1,2}$ Palanisamy Kannan ${ }^{3}$, Zhenyu Lin ${ }^{1}$, Bin Qiu ${ }^{1}$, and Longhua Guo ${ }^{1 *}$

1. Institute of Nanomedicine and Nanobiosensing; The Key Lab of Analysis and Detection Technology for Food Safety of the MOE and Fujian Province; College of Chemistry, Fuzhou University, Fuzhou, 350116, China.

2. Fuqing Entry-Exit Inspection \& Quarantine Bureau of P. R. China, Fuqing, 350300, China.

3. Singapore Centre on Environment Life Sciences Engineering, Nanyang Technological University, 60 Nanyang Drive, SBS-01N-27, 637457, Singapore.

*Correspondence should be addressed to: Prof. Dr. Longhua Guo, email: guolh@,fzu.edu.cn; Tel: +86-591-22866164; Fax: +86-591-22866135 


\section{Experimental details:}

Preparation of Phosphate Buffer Saline (PBS). In our experiments, PBS was prepared by diluting the stock solution with deionized water. The PBS stock solution $(0.2 \mathrm{M}, \mathrm{pH}$ 7.4) was prepared by mixing $19 \mathrm{~mL} \mathrm{NaH} \mathrm{PO}_{4}(0.2 \mathrm{~mol} / \mathrm{L})$ and $81 \mathrm{~mL} \mathrm{Na} \mathrm{HPO}_{4}(0.2$ mol/L). Shortly before use, the PBS stock solution was diluted to the specified concentration with deionized water. Therefore, there was no sodium chloride presented in our PBS buffer.

\section{Detection of Human Alpha Fetoprotein (AFP) via Conventional Sandwich-Format}

\section{ELISA.}

The ELISA test was conducted as follows:

1) $25 \mu \mathrm{L}$ of standards, controls, and serum samples were filled into appropriate wells;

2) $100 \mu \mathrm{L}$ of the incubation buffer was added to the all wells and mix it for $20-30$ seconds;

3) The plates were covered and incubated for 60 minutes at room temperature. Aspirated and washed the wells three times with washing buffer;

4) $100 \mu \mathrm{L}$ of anti-AFP antibody-catalase conjugate was further added into each well. Then the plates were covered and incubated for 30 minutes at room temperature. Aspirated and washed the wells three times with washing buffer again; 
5) $45 \mu \mathrm{L}$ enzymatic reaction solution $\left(8.5 \mathrm{mM} \mathrm{H}_{2} \mathrm{O}_{2}\right.$ in $\left.0.1 \mathrm{M} \mathrm{pH} 7.8 \mathrm{PBS}\right)$ was

dropped into the each wells. Mixed gently, covered the plates and incubated for $10 \mathrm{~min}$ at room temperature;

6) Next, $75 \mu \mathrm{L}$ of AuNRs, $22.5 \mu \mathrm{L}$ of $2 \mathrm{M} \mathrm{HCl}$ and $7.5 \mu \mathrm{L}$ of $20 \mathrm{mM} \mathrm{FeSO}_{4}$ solutions were added into above wells and generate the colorimetric reaction, then, covered the plates and incubated for $15 \mathrm{~min}$ at room temperature;

7) The absorbance spectra of the above solution was measurecd with a 96-well UV-STAR plate (Greiner) at a wavelength range between 300 and $850 \mathrm{~nm}$. Also to take the representative photos of the solution by a DSLR camera (Canon EOS 600D).

\section{Detection of AFB1 via Competitive ELISA.}

The ELISA test was conducted as follows:

1) $50 \mu \mathrm{L}$ of the sample or standard solution was taken into the separate wells; each $50 \mu \mathrm{L}$ of AFB1-catalase conjugate, and antibody working solution was further added into each well, then mixed gently by shaking the plate. Microplate was sealed with the cover membrane, and incubated at room temperature for $30 \mathrm{~min}$. Aspirated and washed the wells three times with washing buffer.

2) $45 \mu \mathrm{L}$ of enzymatic reaction solution ( $8.5 \mathrm{mM} \mathrm{H}_{2} \mathrm{O}_{2}$ in $0.1 \mathrm{M}$ (pH 7.8) PBS) was added into the each wells. Then, mixed gently, covered the plates and incubated for 10 min at room temperature. 
3) $75 \mu \mathrm{L}$ of AuNRs, $22.5 \mu \mathrm{L}$ of $2 \mathrm{M} \mathrm{HCl}$ and $7.5 \mu \mathrm{L}$ of $20 \mathrm{mM} \mathrm{FeSO}_{4}$ solutions

were added into above wells and generate the colorimetric reaction, then covered the plates and incubated for $15 \mathrm{~min}$ at room temperature.

4) Take the representative photos of the solution by a DSLR camera (Canon EOS 600D).

\section{Procedures for the Extraction of miRNA-21 from HeLa Cells with a miRNeasy Mini}

\section{Kit (Qiagen).}

Briefly, pellet the appropriate number of cells by centrifuging at $300 \mathrm{rpm}$ for $5 \mathrm{~min}$. Next, add $700 \mu \mathrm{L}$ of QIAzol Lysis Reagent and then homogenize the cells by vortexing for 1 $\min$. Place the tube containing the homogenate on the benchtop at room temperature for 5 min. Further, add $140 \mu \mathrm{L}$ of chloroform into the tube containing the homogenate and cap it securely. Shake the tube vigorously for $15 \mathrm{sec}$. Place the tube containing the homogenate on the benchtop at room temperature for 2-3 min, centrifuge it for $15 \mathrm{~min}$ at $12,000 \mathrm{rpm}$ at $4^{\circ} \mathrm{C}$, then transfer the upper aqueous phase to a new tube. Add $525 \mu \mathrm{L}$ of $100 \%$ ethanol and mix thoroughly by pipetting up and down several times. Pipette out $700 \mu \mathrm{L}$ of the sample into an RNeasy Mini spin column in a $2 \mathrm{~mL}$ collection tube. Close the lid gently and centrifuge at $10000 \mathrm{rpm}$ for $15 \mathrm{~s}$ at room temperature and discard the flow-through. The remainder of the sample was then pipette into the same tube and centrifuge again at $10000 \mathrm{rpm}$ for $15 \mathrm{sec}$ at room temperature, and discard the flow-through. Add $700 \mu \mathrm{L}$ of Buffer RWT to the RNeasy Mini spin column. Close the lid gently and centrifuge for $15 \mathrm{sec}$ at $10000 \mathrm{rpm}$ to wash the column, discard the 
flow-through. Pipette out $500 \mu \mathrm{L}$ of Buffer RPE onto the RNeasy Mini spin column. Close the lid gently and centrifuge for $15 \mathrm{sec}$ at $10000 \mathrm{rpm}$ to wash the column, discard the flow-through. Then, add another $500 \mu \mathrm{l}$ of Buffer RPE to the RNeasy Mini spin column. Close the lid gently and centrifuge for $2 \mathrm{~min}$ at $10000 \mathrm{rpm}$ to dry the RNeasy Mini spin column membrane. Transfer the RNeasy Mini spin column to a new $1.5 \mathrm{~mL}$ tube. Pipette out $200 \mu \mathrm{L}$ of RNase-free water directly onto the RNeasy Mini spin column membrane. Close the lid gently and centrifuge for $1 \mathrm{~min}$ at $10000 \mathrm{rpm}$ to elute the RNA. 


\section{The Effect of Incubation Time on the Color Changes of $\mathrm{H}_{2} \mathrm{O}_{2}$ Induced Etching of AuNRs.}

We investigated the effect of incubation time on the color changes of $\mathrm{H}_{2} \mathrm{O}_{2}$ induced etching of AuNRs.

$\mathrm{H}_{2} \mathrm{O}_{2}$ with three concentrations were investigated (Figure S1). It can be clearly seen that when a relatively high concentration of $\mathrm{H}_{2} \mathrm{O}_{2}$ (e.g. $5 \mathrm{mM}$ ) were used, the etching process can be finished within $10 \mathrm{~min}$; when the concentration of $\mathrm{H}_{2} \mathrm{O}_{2}$ was relatively low, the etching process was fast in the initial stage. However, the etching speed became slow after incubation for $15 \mathrm{~min}$. Therefore, we chose $15 \mathrm{~min}$ for all the tests.
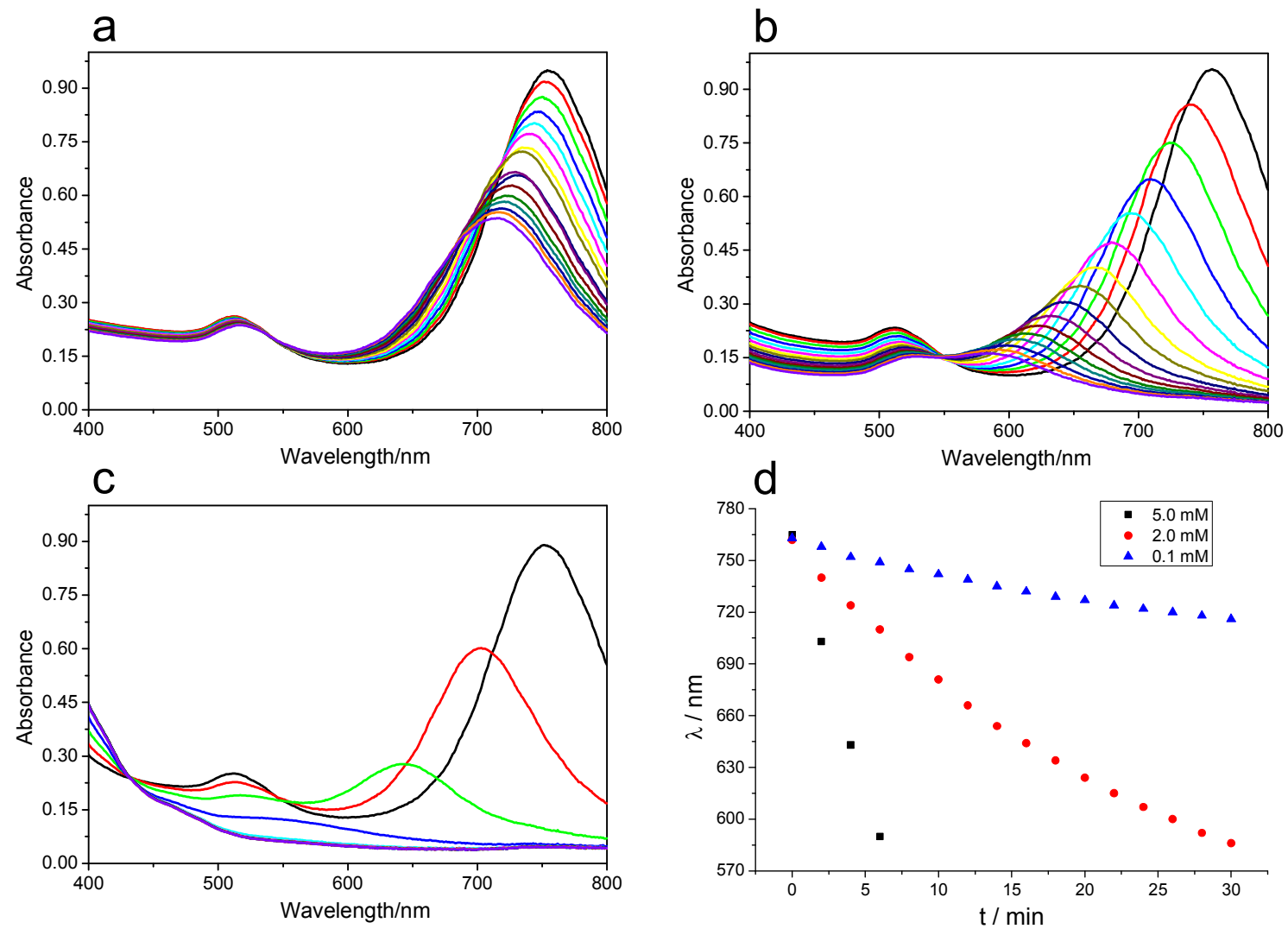
Figure $\mathrm{S} 1$ The effect of incubation time on the color changes of $\mathrm{H}_{2} \mathrm{O}_{2}$ induced etching of AuNRs. a),

(b) and (c) are time-dependant spectral changes of the AuNRs in the presence of 0.1,2.0, and $5.0 \mathrm{mM}$

$\mathrm{H}_{2} \mathrm{O}_{2}$, respectively. (d) is the longitudinal plasmon peak as a function of the incubation time. 


\title{
3. Reproducibility of the Proposed Method for Visual Inspection of
}

\begin{abstract}
AFP.
In order to show the reproducibility of the proposed method, we selected the detection of AFP as a demonstration. As it is shown in Figure S2, AFP in a wide concentration range was tested, and each sample was tested for 4 replicates. It can be clearly seen that good consistency was obtained for all the 8 samples.
\end{abstract}

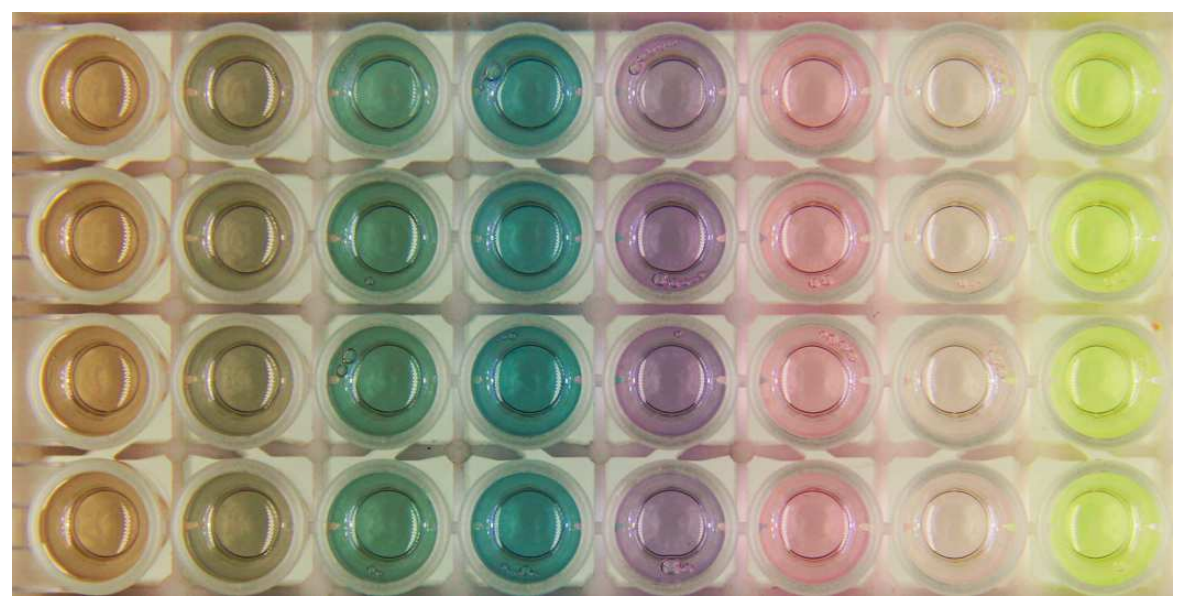

Figure S2 Reproducibility of the proposed method for visual inspection of AFP. Four replicates were conducted for each sample (each column represents one sample). Concentrations of AFP from left to right are $100,95,75,65,55,35,25,18 \mathrm{ng} / \mathrm{mL}$, respectively. 


\section{NEQ-ELISA for the Detection of Clinical Samples.}

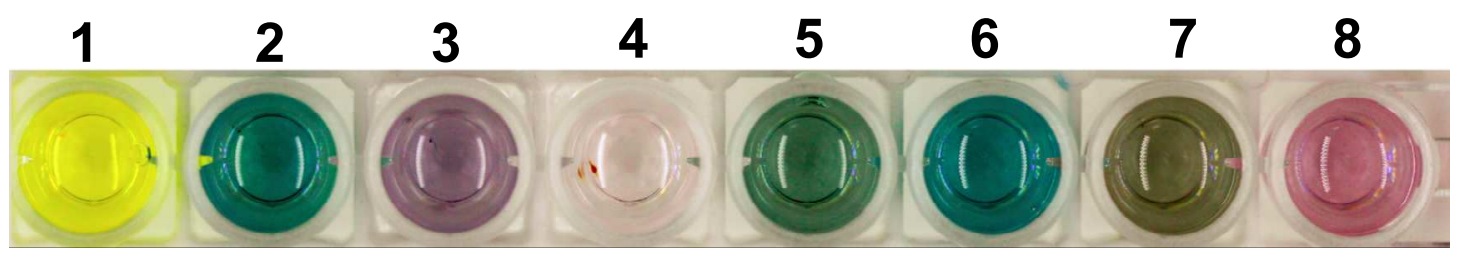

Figure S3 Photographs of the sensor for the detection of 8 clinical samples. Concentrations of AFP determined by the visual quantification were as follow: $17.5,72.5,52.5,22.5,75,65,90$ and $47.5 \mathrm{ng} / \mathrm{mL}$, respectively, corresponding to the sample number of 1 to 8 . 
5. Table S1 Comparison of the Proposed Method and CLIA for the Detection of AFP in 8 Clinical Samples*

\begin{tabular}{ccccccccc}
\hline Test method & \multicolumn{7}{c}{ AFP concentration (ng/mL) } \\
\hline CLIA & 16.8 & 77.5 & 50.2 & 24.8 & 72.6 & 68.5 & 87.8 & 49.0 \\
This method & 17.5 & 72.5 & 52.5 & 22.5 & 75.0 & 65.0 & 90.0 & 47.5 \\
\hline
\end{tabular}

*The clinical samples were obtained from the First Affiliated Hospital of Fujian Medical University, and the CLIA tests were conducted in the hospital. 


\section{Table S2 MiRNA and DNA Oligonucleotides Used in This Work*}

\begin{tabular}{|c|c|}
\hline Oligonucleotide & Sequence ( $5^{\prime}$ to $\left.3^{\prime}\right)$ \\
\hline miRNA-21 & UAG CUU AUC AGA CUG AUG UUG A \\
\hline MNPs probe & 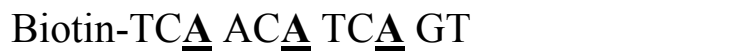 \\
\hline Enzyme-labeled probe & CT $\underline{\mathbf{G}}$ AT $\underline{\mathbf{A}}$ AG $\underline{\mathrm{C}} \mathrm{TA}-\mathrm{NH}_{2}$ \\
\hline single-base mismatched miRNA-21 & UAG CUU AUC AGA CUG AU $\underline{\mathbf{T}}$ UUG A \\
\hline
\end{tabular}

*Underlined blue letter, LNA; underlined red letter, mismatched base. 


\section{Comparison of the Proposed Methods with Other Colorimetric}

\section{Approaches}

In this work, we demonstrated colorimetric detection of AFP, AFB1 and miRNA-21, based on NEQ-ELISA, NEQ-c-ELISA, and NEQ-MIA, respectively. Therefore, herein we compared the detection performance of our methods with those of other colorimetric approaches, and the results are listed in Table S1 (below).

Table S1 Comparison of the proposed methods with other colorimetric approaches for the detection of AFP, AFB1 and miRNA-21.

\begin{tabular}{|c|c|c|c|c|c|}
\hline Target & $\begin{array}{l}\text { Colorimetric } \\
\text { substrate }\end{array}$ & $\begin{array}{c}\text { Number of } \\
\text { displayed } \\
\text { color(s) }\end{array}$ & Dynamic range & LOD & Reference \\
\hline \multirow{4}{*}{ AFP } & $\mathrm{TMB} / \mathrm{H}_{2} \mathrm{O}_{2}$ & Mono-colour & $5 \sim 35 \mathrm{ng} / \mathrm{mL}$ & $0.1 \mathrm{pg} / \mathrm{mL}$ & 1 \\
\hline & AuNPs & Bi-colour & $2 \sim 80 \mathrm{ng} / \mathrm{mL}$ & $2 \mathrm{ng} / \mathrm{mL}$ & 2 \\
\hline & AuNPs & Bi-colour & $50 \sim 1000 \mathrm{pg} / \mathrm{mL}$ & $33.45 \mathrm{pg} / \mathrm{mL}$ & 3 \\
\hline & AuNRs & Mulit-colour & 5 120 ng/mL & $5.0 \mathrm{ng} / \mathrm{mL}$ & This method \\
\hline \multirow{4}{*}{ AFB1 } & AuNPs & Bi-colour & $0.01 \sim 1 \mathrm{ng} / \mathrm{mL}$ & $7 \mathrm{pg} / \mathrm{mL}$ & 4 \\
\hline & $\mathrm{TMB}$ & Mono-colour & $0.05 \sim 150 \mathrm{ng} / \mathrm{mL}$ & $6.5 \mathrm{pg} / \mathrm{mL}$ & 5 \\
\hline & $\mathrm{ABTS} / \mathrm{H}_{2} \mathrm{O}_{2}$ & Mono-colour & $\begin{array}{c}0.1 \sim 1.0 \times 10^{4} \\
\mathrm{ng} / \mathrm{mL}\end{array}$ & $0.1 \mathrm{ng} / \mathrm{mL}$ & 6 \\
\hline & AuNRs & Mulit-colour & $0.02 \sim 0.42 \mathrm{ng} / \mathrm{mL}$ & $0.08 \mathrm{ng} / \mathrm{mL}$ & This method \\
\hline \multirow{3}{*}{$\begin{array}{l}\text { miRNA } \\
-21\end{array}$} & $\mathrm{ABTS} / \mathrm{H}_{2} \mathrm{O}_{2}$ & Mono-colour & $10 \mathrm{aM} 1 \mathrm{nM}$ & $5 \mathrm{aM}$ & 7 \\
\hline & AuNPs & Bi-colour & $1 \mathrm{pm} \sim 10 \mu \mathrm{M}$ & 1 & 8 \\
\hline & AuNRs & Mulit-colour & 5 aM 10 pM & $5 \mathrm{aM}$ & This method \\
\hline
\end{tabular}

It is worth to note that although the LODs of our approach were not impressive, they were sensitive enough for real applications. For example, clinical diagnosis of hepatocellular carcinomas (HCC) accepted a cut-off value of $20 \mathrm{ng} / \mathrm{mL}$ for AFP, thus our 
LOD of $5 \mathrm{ng} / \mathrm{mL}$ can satisfy the clinical requirement for diagnosis of HCC; The Regulatory limit for AFB1 was set to be $5 \mu \mathrm{g} / \mathrm{Kg}$ by the European Union, while our LOD is $0.08 \mathrm{ng} / \mathrm{mL}(\sim 0.08 \mu \mathrm{g} / \mathrm{Kg})$. Therefore, our LOD was more than enough to satisfy the AFB1 detection requirement of the European Union.

More importantly, the LODs of our methods are estimated based on naked-eye inspection, while all other approaches are estimated based on the detection of sophisticated apparatus. Therefore, our methods possess the advantage of simplicity and low cost.

\section{References:}

(1) Wang, J.; Cao, Y.; Xu, Y.; Li, G. Biosens. Bioelectron. 2009, 25, 532-536.

(2) Lu, C.-H.; Wang, Y.-W.; Ye, S.-L.; Chen, G.-N.; Yang, H.-H. NPG Asia Mater. 2012, 4, e10.

(3) Chen, C.; Luo, M.; Ye, T.; Li, N.; Ji, X.; He, Z. Analyst 2015.

(4) Wang, X.; Niessner, R.; Knopp, D. Analyst 2015, 140, 1453-1458.

(5) Lai, W.; Wei, Q.; Xu, M.; Zhuang, J.; Tang, D. Biosens. Bioelectron. 2015.

(6) Seok, Y.; Byun, J.-Y.; Shim, W.-B.; Kim, M.-G. Anal. Chim. Acta 2015, 886, 182-187.

(7) Li, D.; Cheng, W.; Yan, Y.; Zhang, Y.; Yin, Y.; Ju, H.; Ding, S. Talanta 2016, 146, 470-476.

(8) Park, J.; Yeo, J.-S. Chem. Commun. 2014, 50, 1366-1368. 